\title{
The lifting force relationship of a BLDC motor rotor system to the blade rotation speed
}

\author{
Al $\mathrm{Al}^{*}$, Arfita Yuana Dewi² and Taufal Hidayat ${ }^{3}$ \\ Institut Teknologi Padang, Electrical Engineering Department, Padang, Indonesia
}

\begin{abstract}
In developing the knowledge and information about the Quadcopter aircraft, the parameters related to aircraft lift capability factors; fly long; flying high; type of motor; the type of propeller; including the sensors and control systems used. To find out of the BLDC motor voltage source to the rotor angle velocity $(\omega)$ relationship; rotor speed to wind velocity through rotor $(\mathrm{v})$; rotor speed to rotor lift $(\mathrm{Ft})$; wind speed to rotor lift; push the following rotor $(\mathrm{Ct})$. Test and measurement results data show that; the lift force generated with rotational speed relationship is not proportional Nonlinearity occurs when the rotor is released from the self and starts pulling the strain gauge when the rotation speed reaches around $65 \mathrm{rps}$. Once the rotation speed of the rotor is able to reach up to 1.5 Newton lift then the thrust rising trend increasing sharply to the increasing the speed of rotation of the rotor. A special rotor that has BLDC motor specifications such as; $1200 \mathrm{KV}, 12$ Volt and 30 Ampere; blade with a radius of $\mathrm{r} 0.12 \mathrm{~m}$; at a temperature of about $27^{\circ} \mathrm{C}$; in the condition there are no other wind currents then obtained thrust $(\mathrm{Ct})$ of 1.732.
\end{abstract}

\section{Introduction}

Today, Quadcopter aircraft has become a trend of the world's people, whether used as a special purpose or as a hobby. The special use of Quadcopter aircraft such as military interests, the interests of mapping surveys and other purposes such as natural disaster relief ( $\mathrm{Al} \mathrm{Al}$, 2017). The use of Quadcopter as a hobby has spawned a community of Quadcopter maniac societies, almost covering any country in the world as a Quadcopter. The existence of a Quadcopter will become more important to take a bigger role in various purposes, including for business support. They will be an integral part of everyday human life activities, from the simple things to the bigger interests, like defense and security of the region (Parhar 2016).

In the use of Quadcopter, both as a hobby or as a special need are still many obstacles or weaknesses such as; the plane easy to fall; the plane is easy to hit; the battery is not durable; vulnerable to weather conditions and others. In relation to that, Quadcopter's research and development is becoming more and more developed to cover the weaknesses of the existing Quadcopter aircraft as well as to improve aircraft facilities and capabilities (Magnussen, 2015). The vertical take-off landing (VTOL) Aircraft is a type of aircraft that can do take-off and landing perpendicular to the earth so it can be done in a narrow place. The UAV of this type is suitable for the survey location function in a narrow area such as urban residential areas or many shrubs areas ( $\mathrm{Al} \mathrm{Al}$, 2016).

Pounds 2006 has been researching about Pilot, the quadrotor robot chassis and avionics using custom-built motor and battery off-the-shelf, into a highly reliable experimental platform. This vehicle uses the plant dynamics are tuned with mounted on board attitude control to stabilize flight. SISO linear controller is designed to regulate the conduct flyer.

The UAV has more dynamic stability than helicopters. Therefore, this aircraft does not require a special pilot to operate that. They are mostly used in different interests such as logistic purposes, agriculture, fire sensing, military exercises etc. Propeller and BLDC motors are integrated UAV rotor drive devices that generate a drive for takeoff. The process of rotor lift analysis is very complex and complicated. Analysis results this style is important, in choosing a motor for use on the UAV systems (Patel at. al 2017). Tao in 2016, examines the air traffic management system is unmanned. The purpose of this research is to: define the system; current system practices; how pilots use the system, and who has the authority; determine the physical architecture of what is needed in a system that handles a wide variety of aircraft.

In developing the knowledge and information about the Quadcopter aircraft, the data or parameters related to the lifting ability factor of the aircraft; long flight; high fly; type of motor used; the type of propeller used; including the sensors and control systems used. Accordingly, this study proposes to find a relationship between changes in BLDC motor voltage source to rotor angle velocity $(\omega)$; changes in rotor angle velocity to wind speed through the rotor $(v)$; the change in the angular velocity of the rotor to the rotor lifts $(\boldsymbol{F t})$; changes in wind speed to rotor lift; rotor thrust coefficient $(\boldsymbol{C} \boldsymbol{t})$.

\footnotetext{
* Corresponding author: al.mtdrs@gmail.com
} 


\section{Literature Review}

The ability of aircraft to fly in the air is in principle based on; Newton's law; Archimedes; Pascal; Bernoulli, and the law of continuity. Newton's law describes the relationship between forces acting on an object and its motion. The law of Archimedes explains the upward pressure on an object when immersed in a liquid. Pascal's law states that the pressure given to the liquid is passed in all directions.

Bernoulli Law explains that the increase in fluid velocity causes a decrease in pressure on the flow. The Law of Continuity suggests the fact that the mass of the fluid moves will not change when the negative (Hydrodynamics 2006).

Newton's Law I states: every object will remain in perpendicular motion or remain in a static state if there is a resultant, force $(\mathrm{F})$ works on that object:

$$
\sum f=0, a=0, V=0 \text { (konstan) }
$$

Newton's law II, states that the force is equal to the difference in momentum (mass multiplied by the speed) of each time change.

$$
F=m \cdot a
$$

Newton's Law III states: that every action must have a reaction in the same direction and opposite direction $\left(\boldsymbol{F}_{\boldsymbol{l}}\right.$ $=F_{1}$ ).

The law of Archimedes says that: If an object is immersed in a liquid thing, it will be pressured upward as large as the weight of a liquid dampened by it.

$$
\mathbb{F A}=p \cdot Q \cdot v
$$

Where: $\boldsymbol{F} \boldsymbol{A}=$ Archimedes pressure $\left(\mathrm{N} / \mathrm{m}^{3}\right)$

$\boldsymbol{\rho}=$ Mass Type of liquid $\left(\mathrm{Kg} / \mathrm{m}^{3}\right)$

$\boldsymbol{g}=$ Gravitation $(\mathrm{N} / \mathrm{Kg})$

$\boldsymbol{V}=$ Volume of Dyed Objects $\left(\mathrm{m}^{3}\right)$

Pascal's law states that "the pressure given by liquids in a confined space is passed in all directions equally." The difference in pressure due to differences in the increase in the liquid is formulated as follows:

$$
\Delta P=\rho \cdot g \cdot(\Delta H)
$$

Where:

$\Delta \mathrm{P}:$ hydrostatic pressure $(\mathrm{Pa})$

P: fluid speed $\left(\mathrm{kg} / \mathrm{m}^{3}\right)$

$\mathrm{G}$ : sea level rise against earth gravitation $\left(\mathrm{m} / \mathrm{s}^{2}\right)$

$\Delta \mathrm{H}$ : altitude difference of fluid (m)

According to Bernoulli, an increase in the fluid velocity will cause a decrease in pressure on the flow. This principle is actually a simplification of the Bernoulli Equation, which states that the amount of energy at a point in a closed stream is equal to the amount of energy at another point on the same flow path. There are generally two forms of the Bernoulli equation; the first applies to incompressible flow, and the other is for compressible flow fluids.
Incompressible flow is a fluid flow characterized by an unchanged mass density (density) of the fluid along the stream. The form of the Bernoulli Equation for noncompressed streams is as follows:

where:

$$
p+\rho g h+\frac{1}{2} \rho v^{2}=\text { constant }
$$

$v=$ fluid speed

$g=$ earth gravitation

$h=$ altitude relative to a reference

$p=$ fluid pressure

$\rho=$ fluid density

The above equation applies to non-compressed streams with the following assumptions: that the flow is steady state and there is no inviscid friction. In another form, the Bernoulli Equation can be written as follows: $p_{1}+\rho g h_{1}+\frac{1}{2} \rho v_{1}^{2}=p_{2}+\rho g h_{2}+\frac{1}{2} \rho v_{2}^{2}$ (2)

The compressible flow fluid is a fluid flow characterized by changing the mass density of the fluid along the stream. The Bernoulli equation for compressed streams is as follows:

$$
\frac{\omega^{2}}{2}+\phi+\omega=\text { constant }
$$

where:

$\phi=$ gravitational potential energy per unit mass; if gravity is constant then $\phi=g h$

$\phi \quad \omega=$ enthalpy of fluid per mass unit.

$$
\omega=\epsilon+\frac{p}{p}
$$

where: $E$ is the thermodynamic energy per unit mass, also referred to as the specific internal energy.

The moving fluid mass does not change as it flows. This fact leads us to an important quantitative relation called the continuity equation. To clarify the details of this centre pay attention to Figure 1

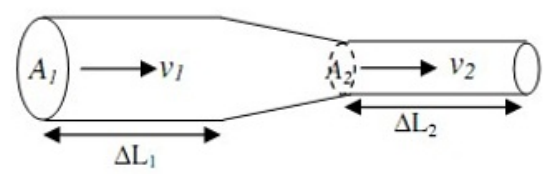

Fig. 1. Mass Flow Rate

The volume of fluid flowing in the first part, V1, which passes through the area of $\mathrm{A} 1$ at rate $\mathrm{v} 1$ over the time range $\Delta \mathrm{t}$ is A1v1 $\Delta \mathrm{t}$. By knowing the relationship of Volume and Mass type, the mass flow rate through the area $\mathrm{A} 1$ is

$$
\frac{\Delta \mathrm{S}}{\Delta t}=\frac{\rho_{1} A_{1} \mathrm{D}_{1} \Delta t}{\Delta t}=\rho_{1} A_{1} D_{1}
$$

The same situation occurs in the second part. The mass flow rate passing through $\mathrm{A} 2$ for the time span $\Delta \mathrm{t}$ is:

$$
P_{2} A_{2} L_{2}
$$


The volume of fluid flowing over the time span $\Delta \mathrm{t}$ in the area A1 will have an amount equal to the volume flowing in A2. Therefore:

$$
\rho_{1} A_{1} W_{1}=\rho_{2} A_{2} V_{2}
$$

or $\rho . A . V$ is constant.

Guido at. all 2016, investigates UAV Uses for capturing reliable GPS technology as a benchmark. Video processing algorithm for vehicle track acquisition based on OpenCV libraries. Assessment of the accuracy of video processing algorithms of an instrumentation vehicle is equipped with high precision GPS.

The video capture experiment was conducted in two case studies. The results of this experiment highlight the flexibility of UAV technology combined with video processing techniques in monitoring real-time traffic data. The Interests area is defined in which all points of the target vehicle trajectory collected through the GPS receiver are mapped.

Comparing this path monitored by the UAV with GPS traces used as a benchmark, the analysis shows that: Root Mean Square Equations Percentage in velocity evaluations equals $3.96 \%$ and $3.57 \%$, for case studies 1 and 2 respectively.

While on the other hand, more deeply analyzes various error ranges such as: camera position; angle of incident; the position of the object or the fetch frame. The results are used for the measurement and eligibility of the obvjek position (Babinec 2016).

Research on lifts and drag force of a UAV by using Computational Fluid Dynamics (CFD) technique is proposed (K. S. Patel et al. 2014), because wind tunnel experiments are very difficult and additional cost more. This technique shows a close proximity to the real experiment.

In the principle, when the aircraft is on the air, there are four main forces acting on the plane, the thrust $\mathrm{T}$, drag D, lift and weight of the plane (weight $\mathrm{W}$ ). The four aerodynamic forces in flight are discussed by George Cayley, 2008

Meanwhile, the quadcopter movements such as back and forth; Left and right; up and down, influenced by variations in direction, speed and acceleration of four rotors. for a quadcopter that has fixed blade parameters that can change is the speed and acceleration of the propeller angle [kranik 2011].

The propeller serves to transfer power by converting rotational motion into thrust to propel a vehicle like an aeroplane, through a mass of air, by rotating two or more twin blades from the main axle. A propeller acts as a rotating wing and produces a force that applies Bernoulli principles and Newton's laws of motion, resulting in a difference in pressure between the front and back or topdown or left-right surfaces.

The size of the blade used in quadcopter varies depending on the size of the quadcopter and the load to be lifted by the quadcopter. Therefore, to take into account how much the lifting power and the speed of a quadcopter it is important to know a relation between size, rotational speed with the lift of a propeller. The relationship between lift power size and speed such as equation 6 and 7 [Brandt, 2011].

$$
T=\left(C_{t} \cdot \pi \cdot \rho \cdot r^{2} \cdot v^{2}\right) / 2
$$

On the line, Coefficient thrust $\left(\boldsymbol{C}_{\boldsymbol{t}}\right)$ can be expressed as equation 7 .

$$
C_{t}=2 . T /\left(\pi \cdot \rho \cdot r^{2} \cdot v^{2}\right)
$$

Where: $\boldsymbol{C}_{\boldsymbol{t}}$ is thrust coefficient; $\boldsymbol{T}$ is rotor thrust; $\boldsymbol{\pi}$ is 3.14 ; $\boldsymbol{\rho}$ is density of air $=1.225 ; \boldsymbol{r}$ is radius of blade; $\boldsymbol{v}$ is air speed.

\section{Methodology}

In this study, empirical testing was done in the laboratory to find out the relationship amongst other things: changes in BLDC motor voltage source to rotor angle velocity $(\omega)$; changes in rotor angle velocity to wind speed through the rotor $(v)$; the change in the angular velocity of the rotor to the rotor lifts $(\boldsymbol{F t})$; changes in wind speed to rotor lift; rotor thrust coefficient $(\boldsymbol{C t})$.

To obtain the results of these measurements than required materials and equipment as follows:

- $1200 \mathrm{Kv}$ BLDC Motor

- 30 Amper Electronic speed controller (ESC)

- Voltage sensor

- $500 \mathrm{~K}$ Ohm Potentiometer

- Arduino Uno Microcontroller

- Mekanik stand up

- LCD display

- Blade propeller with radius (r) is 0.12 meter

- Digital Anemometer

- Digital Tachometer

- Digital Strain Gauge

Implementation of this rotor parameter measurement is done in accordance with the block diagram as in Figure 2.

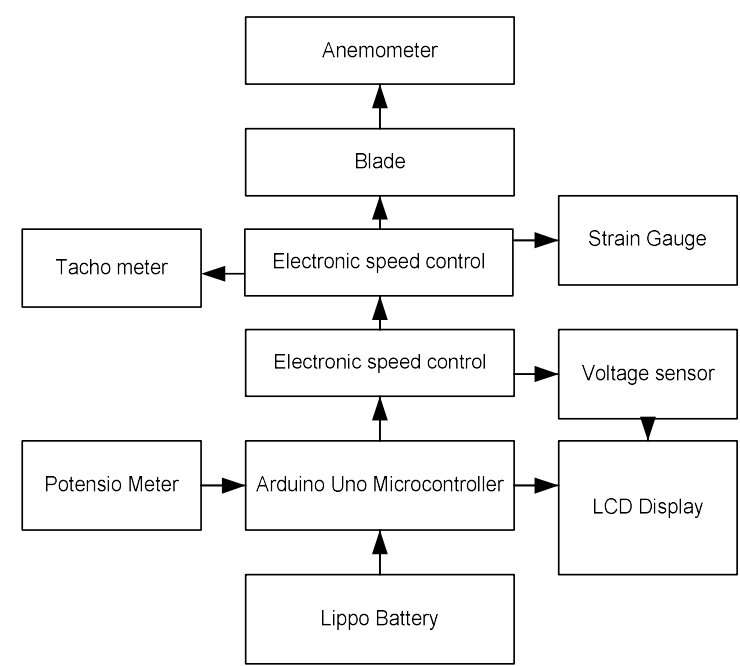

Fig. 2. Block diagram of measurement system 
The material and measurement equipment are shown as in Figure 3.

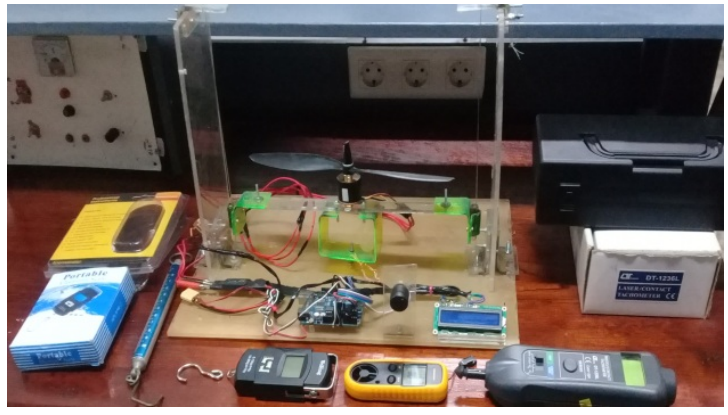

Fig. 3. The material and measurement equipmen

\section{Result and discussion}

For the first time, rotor parameters were measured only by self-loading weighing 165 grams. Overall the results are shown in Table 1.

Table 1. Self-Load

\begin{tabular}{|c|c|c|c|c|c|}
\hline No. & $\begin{array}{l}\text { Voltage } \\
\text { source } \\
\text { (Volt) }\end{array}$ & $\begin{array}{l}\text { Rotor } \\
\text { Speed } \\
\text { (rpm) }\end{array}$ & $\begin{array}{c}\text { Device } \\
\text { condition }\end{array}$ & $\begin{array}{l}\text { Airspee } \\
\text { d km/h }\end{array}$ & $\begin{array}{c}\text { Airspee } \\
\mathrm{d} \mathrm{m} / \mathbf{s}\end{array}$ \\
\hline 1 & 1 & 0 & stag & 0 & 0 \\
\hline 2 & 1.5 & 0 & stag & 0 & 0 \\
\hline 3 & 2 & 0 & stag & 0 & 0 \\
\hline 4 & 2.26 & 964 & stag & 6.8 & $\begin{array}{r}1.88888 \\
9\end{array}$ \\
\hline 5 & 2.5 & 2008 & stag & 13.7 & $\begin{array}{r}3.80555 \\
6 \\
\end{array}$ \\
\hline 6 & 2.7 & 2633 & stag & 17.9 & $\begin{array}{r}4.97222 \\
2 \\
\end{array}$ \\
\hline 7 & 2.85 & 2935 & stag & 19.3 & $\begin{array}{r}5.36111 \\
1 \\
\end{array}$ \\
\hline 8 & 2.86 & 2972 & cut in half & 20.3 & $\begin{array}{r}5.63888 \\
9 \\
\end{array}$ \\
\hline 9 & 2.96 & 3209 & cut in half & 21.4 & $\begin{array}{r}5.94444 \\
4\end{array}$ \\
\hline 10 & 3 & 3339 & cut in half & 22.3 & $\begin{array}{r}6.19444 \\
4 \\
\end{array}$ \\
\hline 11 & 3.1 & 3539 & go up & 23.5 & $\begin{array}{r}6.52777 \\
8\end{array}$ \\
\hline 12 & 3.15 & 3627 & go up & 24.2 & $\begin{array}{r}6.72222 \\
2\end{array}$ \\
\hline 13 & 3.25 & 3823 & go up & 25.1 & $\begin{array}{r}6.97222 \\
2 \\
\end{array}$ \\
\hline 14 & 3.35 & 3957 & go up & 26 & $\begin{array}{r}7.22222 \\
2 \\
\end{array}$ \\
\hline 15 & 3.5 & 4230 & go up & 28.3 & $\begin{array}{r}7.86111 \\
1 \\
\end{array}$ \\
\hline 16 & 3.8 & 4643 & go up & 29.8 & $\begin{array}{r}8.27777 \\
8\end{array}$ \\
\hline 17 & 4 & 4896 & go up & 32.3 & $\begin{array}{r}8.97222 \\
2 \\
\end{array}$ \\
\hline 18 & 4.5 & 4967 & go up & 34.2 & 9.5 \\
\hline 19 & 5 & 5285 & go up & 36.9 & 10.25 \\
\hline
\end{tabular}

By observing Table 1 it can be seen that: providing a source ranging from 1 to 2 volts can not move propellers; by providing a source voltage between 2.26 to 2.85 volts the propeller has been able to spin but has not had the power to self-immerse; after being given between 2.86 to 3-volt rotor conditions are now floating or starting to lift. At the moment the source voltage is given as much as 3.1-volt and the rotor has been lifted and higher. The start of the rotor lift is marked by the rotor rotation speed of $3539 \mathrm{rpm}$. While the highest angular spin speed reaches $5285 \mathrm{rpm}$ when given 5 volts source voltage.

Next, the rotor parameters were tested with self-loads added with a load of 50 grams, bringing the total load to 215 grams and its content shown as in Table 2.

Table 2 Measurement With 215-Gram Load

\begin{tabular}{|c|c|c|c|}
\hline N0 & $\begin{array}{c}\text { Voltage } \\
\text { Source }\end{array}$ & Speed (rpm) & Device \\
\hline $\mathbf{0}$ & $\mathbf{0}$ & 0 & Condition \\
\hline $\mathbf{1}$ & 1 Volt & 0 & stagnan \\
\hline $\mathbf{2}$ & 1,50 Volt & 0 & stagnan \\
\hline $\mathbf{3}$ & 2 Volt & 0 & stagnan \\
\hline $\mathbf{4}$ & 2,26 Volt & 964 & stagnan \\
\hline $\mathbf{5}$ & 2,50 Volt & 2008 & stagnan \\
\hline $\mathbf{6}$ & 2,70 Volt & 2633 & stagnan \\
\hline $\mathbf{7}$ & 2,85 Volt & 2935 & stagnan \\
\hline $\mathbf{8}$ & 2,86 Volt & 2972 & stagnan \\
\hline $\mathbf{9}$ & 2,96 Volt & 3209 & stagnan \\
\hline $\mathbf{1 0}$ & 3 Volt & 3339 & stagnan \\
\hline $\mathbf{1 1}$ & 3,10 Volt & 3539 & stagnan \\
\hline $\mathbf{1 2}$ & 3,14 Volt & 3612 & stagnan \\
\hline $\mathbf{1 3}$ & 3,15 Volt & 3562 & cutinhalf \\
\hline $\mathbf{1 4}$ & 3,25 Volt & 3733 & go-up \\
\hline $\mathbf{1 5}$ & 3,35 Volt & 3888 & go-up \\
\hline $\mathbf{1 6}$ & 3,50 Volt & 4034 & go-up \\
\hline $\mathbf{1 7}$ & 3,80 Volt & 4577 & go-up \\
\hline $\mathbf{1 8}$ & 4 Volt & 4708 & go-up \\
\hline $\mathbf{1 9}$ & 4,50 Volt & 4856 & go-up \\
\hline $\mathbf{2 0}$ & 5 Volt & 5185 & go-up \\
\hline
\end{tabular}

With a load of 215 grams, it can be seen in table 2 that; between 1 to 3.14 volts source voltage, the rotor cannot be lifted. When given a 3.15-volt source voltage then the aircraft starts to float. Starting from the 3.25volt source voltage and rushing up the rotor is already up and moving higher.

Furthermore, by providing a total weight of 315 grams, the result of the parameter measurement is shown as in Table 3. Table 3 shows that the rotor floats when the source voltage is given at 3.78 volts. Whereas, after the source voltage is given by 3.8 volts continues up to 5 volts, the rotor is raised and the higher. 
Table 3 Measurement With 315-Gram Load

\begin{tabular}{|c|c|c|c|}
\hline \multicolumn{1}{|c}{ Table 3 Measurement With 315-Gram Load } \\
N0 & Voltage source & $\begin{array}{c}\text { Rotor } \\
\text { Speed (rpm) }\end{array}$ & $\begin{array}{c}\text { Device } \\
\text { condition }\end{array}$ \\
\hline & $1 \quad$ Volt & 0 & stag \\
\hline $\mathbf{2}$ & 1,50 Volt & 0 & stag \\
\hline $\mathbf{3}$ & 2 Volt & 0 & stag \\
\hline $\mathbf{4}$ & 2,26 Volt & 964 & stag \\
\hline $\mathbf{5}$ & 2,50 Volt & 2008 & stag \\
\hline $\mathbf{6}$ & 2,70 Volt & 2633 & stag \\
\hline $\mathbf{7}$ & 2,85 Volt & 2935 & stag \\
\hline $\mathbf{8}$ & 2,86 Volt & 2972 & stag \\
\hline $\mathbf{9}$ & 2,96 Volt & 3209 & stag \\
\hline $\mathbf{1 0}$ & 3 Volt & 3339 & stag \\
\hline $\mathbf{1 1}$ & 3,10 Volt & 3539 & stag \\
\hline $\mathbf{1 2}$ & 3,14 Volt & 3612 & stag \\
\hline $\mathbf{1 3}$ & 3,15 Volt & 3562 & stag \\
\hline $\mathbf{1 4}$ & 3,25 Volt & 3716 & stag \\
\hline $\mathbf{1 5}$ & 3,34 Volt & 3788 & stag \\
\hline $\mathbf{1 6}$ & 3,35 Volt & 3823 & stag \\
\hline $\mathbf{1 7}$ & 3,50 Volt & 3977 & stag \\
\hline $\mathbf{1 8}$ & 3,77 Volt & 4317 & stag \\
\hline $\mathbf{1 9}$ & 3,78 Volt & 4355 & floating \\
\hline $\mathbf{2 0}$ & 3,80 Volt & 4419 & go-up \\
\hline $\mathbf{2 1}$ & 4 Volt & 4581 & go-up \\
\hline $\mathbf{2 2}$ & 4,50 Volt & 4622 & go-up \\
\hline $\mathbf{2 3}$ & 5 Volt & 5079 & go-up \\
\hline
\end{tabular}

Hereinafter, the measurement of rotor parameters with a total load of 365 grams, the results are shown in Table 4. The data in Table 4 shows that the source voltage between 1 to 3.8 volts has not been able to hold the rotor along with the load. The rotor begins to float at a given source voltage of 3.81 volts with a rotor rotation speed of $4355 \mathrm{rpm}$.

By providing a voltage source of 3.8 2volts to produce a rotor rotation speed of 4492-rpm rotor start moving upward, and so on the addition of source voltage up to 5 volts increase the speed of the rotor is marked with a peak rotation speed of $5079 \mathrm{rpm}$.

By examining the results of the test table 1 already with table 4 , it is directly indicated that the increase in source voltage raises the increase to the speed of rotation of the rotor. The speed of rotation of the rotor makes the air velocity through it is proportional. The air velocity through the rotor is what will generate the rotor lift, according to the concept proposed by; Newton's law; Archimedes; Pascal; Bernoulli, and the law of continuity.

To know directly the relationship between; rotation speed of the rotor with a voltage source; speed of rotation of the rotor with wind speed and the rotation speed of the rotor to the resulting thrust, then continued simultaneous testing as a further explanation.

Table 4. Measurement With 365-Gram Load

\begin{tabular}{|c|c|c|c|}
\hline No & $\begin{array}{c}\text { Voltage } \\
\text { source }\end{array}$ & $\begin{array}{c}\text { Rotor Speed } \\
\text { (rpm) }\end{array}$ & $\begin{array}{c}\text { Device } \\
\text { condition }\end{array}$ \\
\hline 1 & 1 Volt & 0 & 200 \\
\hline 2 & 1,50 Volt & 0 & 200 \\
\hline 3 & 2 Volt & 0 & 200 \\
\hline 4 & 2,26 Volt & 964 & 200 \\
\hline 5 & 2,50 Volt & 2008 & 200 \\
\hline 6 & 2,70 Volt & 2633 & 200 \\
\hline 7 & 2,85 Volt & 2935 & 200 \\
\hline 8 & 2,86 Volt & 2972 & 200 \\
\hline 9 & 2,96 Volt & 3209 & 200 \\
\hline 10 & $3 \quad$ Volt & 3339 & 200 \\
\hline 11 & 3,10 Volt & 3539 & 200 \\
\hline 12 & 3,14 Volt & 3612 & 200 \\
\hline 13 & 3,15 Volt & 3562 & 200 \\
\hline 14 & 3,25 Volt & 3716 & 200 \\
\hline 15 & 3,34 Volt & 3788 & 200 \\
\hline 16 & 3,35 Volt & 3823 & 200 \\
\hline 17 & 3,50 Volt & 3977 & 200 \\
\hline 18 & 3,77 Volt & 4317 & 200 \\
\hline 19 & 3,78 Volt & 4355 & 200 \\
\hline 20 & 3,80 Volt & 4419 & 200 \\
\hline 21 & 3,81 Volt & 4578 & floating \\
\hline 22 & 3,82 Volt & 4492 & Go-up \\
\hline 23 & $4 \quad$ Volt & 4523 & 200 \\
\hline 24 & $4,50 \quad$ Volt & 4611 & 200 \\
\hline 25 & 5 Volt & 4944 & 200 \\
\hline
\end{tabular}

The rotor angular velocity and voltage source relationship test, the wind speed and the lift produced by the rotor are performed with stand up as Figure 4.

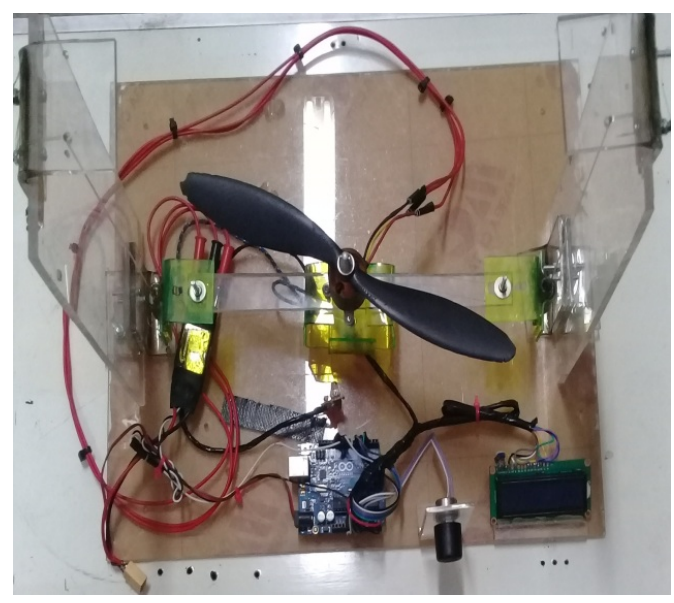

Fig. 4. Rotor under testing 
The preparations and test instruments in FIG. 1 comprises blades with a radius of $0.0645 \mathrm{~m}$; BLDC Motor $1200 \mathrm{Kv}$; Electronic speed controller (ESC); Arduino microcontroller UNO; Lithium 30 A 5 V Battery; LCD display as an indicator of the voltage source; Anemometer; Digital Tachometer and Digital strain gauge.

While the test results between the rotor angular velocities to the voltage source obtained the results such as graphs in Figure 5.

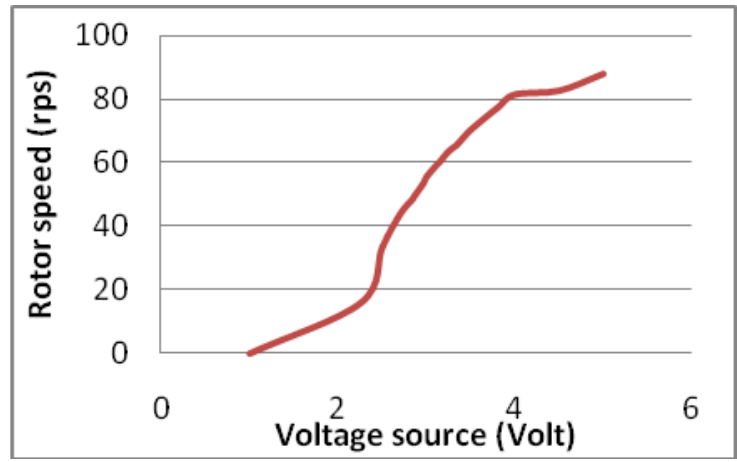

Fig. 5. Rotor speed vs Voltage source

The graphic of Figure 5 shows that the increase in voltage source raises the rotor speed but this increase is not liner as long as the increase in voltage source. Between 2.8 volts up to 4 volts, the rotor speed has a linear almost increase.

The results of the air velocity testing of the rotor speed are shown in the graph of figure 6. This graph illustrates that the increase in rotor speed produces air velocity proportional to the linear trend during the change.

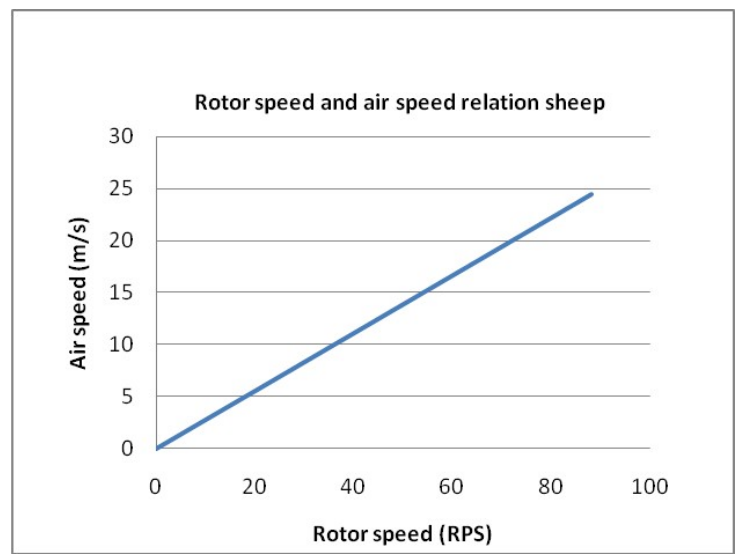

Fig. 6. Rotor and Air Speed Relationship

Measurement of the rotor lift to the change in rotation speed of the rotor angle is done by measuring instrument of the digital strain gauge and digital tachometer. The result is shown in the graph in figure 7 . Figure 4 states that the increase in rotor speed causes an increase in the rotor thrust. the relationship of both parameters increase is not linear at all. On the graph shows that between zero to $60 \mathrm{rps}$ starts with a linear trend, between 65 up to 75 rps trend occurs bend and after that greater than 75 rps obtained linear trend back. In a non-linear condition between 65 and $75 \mathrm{rps}$, a change of thrust state is used only to elevate itself until it begins to draw the strain gauge as a measure of the rotor's lift power.

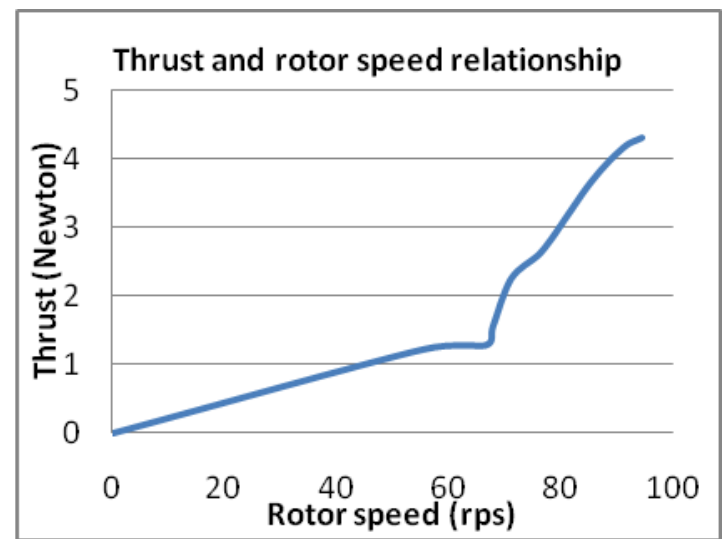

Fig. 7. A thrust and Rotor Speed Selationship

By using $1200 \mathrm{Kv} / 5$ Volt BLDC motor and blade which is has a radius $\mathrm{r} 0.12 \mathrm{~m}$, and then according to equation $C_{t}=2 . T /\left(\pi \cdot \rho \cdot r^{2} \cdot v^{2}\right)$ is obtained by the thrust coefficient $\left(\mathrm{C}_{\mathrm{t}}\right)$ according to the wind speed as shown in the Table 5. Where: $\boldsymbol{C}_{\boldsymbol{t}}$ is thrust coefficient; $\boldsymbol{T}$ is rotor thrust; $\boldsymbol{\pi}$ is $3.14 ; \boldsymbol{\rho}$ is the density of air $=1.225 ; \boldsymbol{r}$ is the radius of the blade; $\boldsymbol{v}$ is airspeed.

Table 3 Average of $C t$ From Thrust and Air Speed $v$

\begin{tabular}{|c|c|c|c|c|c|}
\hline $\begin{array}{c}\text { Total } \\
\text { thrust } \\
\text { (Newto } \\
\text { n }\end{array}$ & $\begin{array}{l}\text { Airspee } \\
\text { d (m/s) }\end{array}$ & $\pi$ & $\rho$ & $\begin{array}{l}\underset{(m)}{\operatorname{radius}} r \\
\end{array}$ & $\begin{array}{c}\text { Coefficien } \\
\text { t Thrust } \\
\text { (Ct) }\end{array}$ \\
\hline 0 & 0 & 0 & 0 & 0 & 0 \\
\hline 1.225 & 5.5 & 3.14 & 1.225 & 0.12 & 1.462219 \\
\hline 1.225 & 5.9 & 3.14 & 1.225 & 0.12 & 1.270673 \\
\hline 1.2838 & 6 & 3.14 & 1.225 & 0.12 & 1.287646 \\
\hline 1.568 & 6.2 & 3.14 & 1.225 & 0.12 & 1.47287 \\
\hline 2.254 & 6.5 & 3.14 & 1.225 & 0.12 & 1.926322 \\
\hline 2.597 & 7 & 3.14 & 1.225 & 0.12 & 1.913717 \\
\hline 2.842 & 7.5 & 3.14 & 1.225 & 0.12 & 1.82433 \\
\hline 3.675 & 8 & 3.14 & 1.225 & 0.12 & 2.073381 \\
\hline 4.165 & 8.5 & 3.14 & 1.225 & 0.12 & 2.081512 \\
\hline 4.312 & 9 & 3.14 & 1.225 & 0.12 & 1.922186 \\
\hline \multicolumn{5}{|r|}{ Total $\mathrm{Ct}$} & 17.23486 \\
\hline \multicolumn{5}{|c|}{ Average $\mathrm{Ct}$} & 1.723486 \\
\hline
\end{tabular}

After measuring more than 20 times, the average measurement value as shown in Table 5. Table 5 gives information that the conversion of wind speed generated by the rotor produces a comparable thrust.

Convertible results are influenced by many factors such as; the size and shape of the blade; earth gravitation; density of air; and constant changes. With 
blade conditions as described earlier and at an ambient temperature of $27^{\circ}$ Celsius the coefficient of this rotor $(\mathrm{Ct})$ of 1.723 is obtained.

\section{Conclusion}

After doing the measurement, testing and analysis of data then it can be concluded as follows. The increase in the rotation speed of the rotor is proportional to the increase of the source voltage applied to the motor bldc and the increase is not always linear as long as the voltage changes from 1 to 5 volts. The linear range occurs between 2.5 to 4 volts. The relationship between rotation speed and the resulting airspeed is proportional to the trend of linear.

The relationship between lift powers produced with rotational speed is not comparable. The nonlinearity occurs when the root is relieved of the weight of oneself and proceeds to start pulling the strain gauge when the rotation speed reaches around $65 \mathrm{rps}$. Once the rotation speed of the rotor is able to generate lift to reach 1.5 Newton then increase the endurance rotor has sharp increasingly.

Using a BLDC motor which is specifications as $1200 \mathrm{Kv}, 12$ Volt and 30 Ampere; blade with a radius of r $0.12 \mathrm{~m}$; at a temperature of about $27^{\circ} \mathrm{C}$; in the condition is no other wind currents then obtained the thrust coefficient $(C t)$ of 1.732 .

\section{ACKNOWLEDGMENT}

I would like to thank the Ministry of Research, Technology and Higher Education of Republic Indonesia and Institut Teknologi Padang in supporting this research.

\section{References}

1. A. Al, A.Y.D. Rachman, J.A. Saputro, Quadcopter capability development for additional low voltage distribution network location tracking, In International conference of applied science on engineering, business, linguistics and information technology, Padang-Indonesia, October $14^{\text {th }}$, (2017)

2. P. Parihar, P. Bhawsar, P. Hargod, Design \& Development Analysis of Quadcopter, COMPUSOFT, An international journal of advanced computer technology, 5 (6), June (2016)

3. O. Magnussen, M. Ottestad, G. Hovland, Multicopter Design Optimization and Validation", Modeling, Identification and Control, Vol. 36, No. 2, pp. 67-79, ISSN 1890-1328. (2015)

4. A. Al, "An Improved a Quadcopter Capability for Forestall Bump with The Ultrasonic HC SR04 Proximity Sensor Design," In International
Conference on Technology, Innovation, and Society (ICTIS), (2016)

5. Pounds, P., Mahony, R., and Corke, P., "Modelling and Control of a Quad-Rotor Robot," In Proceedings of the Australasian Conference on Robotics and Automation, (2006)

6. Y. Patel, A. Gaurav, K. Srinivas, Y. Singh, A Review on Design and Analysis of the propeller used in UAV. In International Journal of Advanced Production and Industrial Engineering, IJAPIE-SIIDCM 605, 20-23, (2017)

7. T. Jiang, J. Geller, Daiheng Ni, John Collura," Unmanned Aircraft System traffic management: Concept of operation and system architecture," International Journal of Transportation Science and Technology 5 123-135. (2016)

8. G. Guido, V. Gallelli, D. Rogano, A. Vitale, Evaluating the accuracy of vehicle tracking data obtained from Unmanned Aerial Vehicles In International Journal of Transportation Science and Technology, 5 pp.136-151, (2016)

9. A. Babinec, J. Apeltauer, "On accuracy of position estimation from aerial imagery captured by lowflying UAVs", International Journal of Transportation Science and Technology, 5 pp. 152166, (2016)

10. S.P. Karana, B.P. Saumil, CFD Analysis of an Aerofoil, In International Journal of Engineering Research, Volume No.3, Issue No.3, pp. 154-158, (2014)

11. T. Krajnık, V. Vonasek, D. Fiser, J. Faigl, ARDrone as a Platform for Robotic Research, The Gerstner Laboratory for Intelligent Decision Making and Control Department of Cybernetics, Faculty of Electrical Engineering Czech Technical University, Prague, (2011)

12. J.B. Brandt, M.S. Selig, Propeller Performance Data at Low Reynolds Numbers, 49th AIAA Aerospace Sciences Meeting, AIAA Paper 20111255, Orlando, FL, January (2011) 